\title{
Tyrosine Kinase Inhibition Ameliorates the Hyperdynamic State and Decreases Nitric Oxide Production in Cirrhotic Rats with Portal Hypertension and Ascites
}

\author{
Juan Carlos López-Talavera, ${ }^{\star}$ Alexander Levitzki, ${ }^{\ddagger}$ Moisés Martínez, ${ }^{\star}$ Aviv Gazit, ${ }^{\ddagger}$ Rafael Esteban, ${ }^{\star}$ and Jaime Guardia* \\ *Liver Unit, Hospital Vall d’Hebrón, Barcelona, Spain; and ${ }^{\ddagger}$ Department of Biological Chemistry, The Hebrew University, \\ Jerusalem, Israel
}

\begin{abstract}
Tumor necrosis factor- $\alpha$ (TNF) causes vasodilatation and a hyperdynamic state by activating nitric oxide (NO) synthesis. Tyrphostins, specific inhibitors of protein tyrosine kinase (PTK), block the signaling events induced by TNF and NO production. A hyperdynamic circulatory syndrome (HCS) is often observed in portal hypertension (PHT). TNF and NO seem to mediate these hemodynamic changes. The aim of this work was to study the effect of PTK inhibition on the systemic and portal hemodynamics, TNF and NO production, in cirrhotic rats with portal hypertension. Rats with liver cirrhosis induced by chronic inhalation of carbon tetrachloride were used. Animals were treated daily with tyrphostin AG 126 ( $\alpha$-cyano-(3-hydroxy-4-nitro) cinnamonitrile) or placebo for $5 \mathrm{~d}$. Mean arterial pressure (MAP), heart rate (HR), and portal pressure (PP) were measured by indwelling catheters. Cardiac output (CI) and stroke volume (SV) were estimated by thermodilution, systemic vascular resistance (SVR) was calculated (MAP/CI), and portal systemic shunting (PSS) was quantitated using radioactive microspheres. Serum and mesenteric lymph node (MLN) TNF levels were measured using an immunoassay kit, and serum NOx was determined photometrically by its oxidation products. The AG 126-treated group showed a statistically significant increase in MAP and SVR, and decreases in CI, SV, MLN TNF, and serum NO oxidation products nitrite and nitrate (NOx) in comparison with the placebotreated rats. No significant differences were noticed in HR, PP, PSS, or serum TNF. Significant correlations were observed between MAP and NOx, MAP and MLN TNF, PSS and NOx, and serum TNF and serum NOx. The HCS observed in PHT seems to be mediated, at least in part, by TNF and NO by the activation of PTKs and their signaling pathways. PTK activity inhibition ameliorates the hyperdynamic abnormalities that characterize animals with cirrhosis and PHT. (J. Clin. Invest. 1997. 100:664-670.) Key words: tumor necrosis factor- $\alpha$ vasodilation - protein tyrosine kinase $\bullet$ signal transduction $\bullet$ liver cirrhosis
\end{abstract}

Address correspondence to Dr. Juan Carlos López-Talavera, Hospital General Vall d'Hebrón, Paseo Vall d'Hebrón 119-129, 08035 Barcelona, Spain. Phone: 34-3-418-3400 ext. 4454; FAX 34-3-428-1417.

Received for publication 28 August 1996 and accepted in revised form 23 April 1997.

J. Clin. Invest.

(c) The American Society for Clinical Investigation, Inc. 0021-9738/97/08/0664/07 \$2.00

Volume 100, Number 3, August 1997, 664-670

http://www.jci.org

\section{Introduction}

Portal hypertension (PHT) ${ }^{1}$ and/or extensive portal-systemic shunting (anatomical or functional) (PSS) is observed very often in patients with chronic liver disease as well as experimental models of this pathology. These patients present with a systemic and splanchnic vasodilatation, retention of sodium and water, and the consequent expansion of the plasma volume, leading to so-called hyperdynamic circulatory syndrome (HCS). This phenomenon is manifested by a decrease in mean arterial pressure (MAP) and systemic vascular resistance (SVR), and an increase in cardiac output and regional blood flows (1). The etiology of the hyperdynamic circulation is still controversial, although it most likely is initiated by vasodilatation induced by an increase in activity of endothelial-dependent and -independent vasodilators.

Several authors have suggested a role for endogenous nitric oxide (NO) in the regulation of vascular tone and blood flow of the systemic and splanchnic circulations in PHT (2, 3), and, by using NO biosynthesis inhibitors, it is possible to attenuate the systemic hypotension and splanchnic vasodilatation observed in rats with PHT $(4,5)$.

TNF- $\alpha$, a $17-\mathrm{kD}$ cytotoxic protein produced by mononuclear cells upon activation by several stimuli (6), has been shown to increase vascular permeability (7), enhance neutrophil adhesion to vascular endothelium (8), promote neutrophil migration to the site of inflammation and injury (8), and cause metabolic and structural damage in vascular endothelial cells $(9,10)$. The biological response to TNF- $\alpha$ is amplified by the secondary release of platelet-derived growth factor (11), granulocyte colony-stimulating factor (11), IL-1 (11), platelet-activating factor $(11)$, and NO $(12,13)$. TNF- $\alpha$ causes marked hypotension in mammals (6). Several investigators have demonstrated the existence of a cytokine-inducible L-arginine/NO pathway by showing that the hypotension elicited by TNF- $\alpha$ is reversed after inhibition of NO synthesis $(14,15)$, which suggests that L-arginine-derived NO is a principal mediator of TNF- $\alpha$-induced hypotension. Several reports have documented elevated TNF- $\alpha$ plasma levels in liver disease $(16,17)$. We have reported recently that treatment with a specific polyclonal anti-TNF- $\alpha$ antibody or with thalidomide, a derivative of glutamic acid that selectively inhibits TNF- $\alpha$ production, significantly blunts the development of the hyperdynamic circulation in partial portal vein ligated (PVL) rats $(18,19)$.

1. Abbreviations used in this paper: CI, cardiac index; HCS, hyperdynamic circulatory syndrome; HR, heart rate; MAP, mean arterial pressure; MLN, mesenteric lymph nodes; NO, nitric oxide; NOx, NO oxidation products nitrite and nitrate; PHT, portal hypertension; PP, portal pressure; PSS, portal-systemic shunting; PTK, protein tyrosine kinase; PVL, portal vein ligated; SV, stroke volume; SVR, systemic vascular resistance. 
Some other hyperdynamic states, such as sepsis or septic shock, result almost exclusively from the stimulation of immunocytes by LPS. LPS induces protein tyrosine phosphorylation in target cells and activates mononuclear cells to produce TNF- $\alpha$ and other inflammatory mediators (20). Moreover, these cytokines induce tyrosine phosphorylation in specific cells that initiate a number of signal events that lead to the synthesis of other intermediary substances, such as NO (20-22). Consequently, specific protein tyrosine kinase (PTK) inhibitors, such as tyrphostins, may offer a double block by inhibiting not only $\mathrm{TNF}-\alpha$ production, but $\mathrm{TNF}-\alpha$ activity as well (23).

In this study, we investigate the effects of the tyrphostin AG 126 ( $\alpha$-Cyano-(3-hydroxy-4-nitro) cinnamonitrile) family of PTK inhibitors on the systemic and portal hemodynamics, TNF- $\alpha$ and NO production, in cirrhotic rats with PHT and ascites.

\section{Methods}

Induction of cirrhosis by carbon tetrachloride $\left(\mathrm{CCl}_{4}\right)$. The experiments were performed on male Sprague-Dawley rats (Letica-Centre d'elevage R. Janvier, Barcelona, Spain) weighing 100-125 g that underwent inhalation exposure to $\mathrm{CCl}_{4}$ as previously described $(24,25)$. The rats were housed in Plexiglas cages in a temperature- and humidity-controlled environment and allowed free access to water and rat chow (Letica). To reduce the time required to induce cirrhosis, rats received $0.35 \mathrm{~g} /$ liter phenobarbital diluted in the drinking water starting $1 \mathrm{wk}$ before initial exposure to $\mathrm{CCl}_{4}$ inhalation. $\mathrm{CCl}_{4}$ was administered in an inhalation chamber three times per week for increasing periods of time (1-5 min). This technique produces a high yield of micronodular cirrhosis after $\sim 12 \mathrm{wk} \mathrm{CCl}_{4}$ inhalation. To overcome variabilities inherent in this model, only animals with clinical evidence of ascites were used for the studies. Phenobarbital was stopped at least $6 \mathrm{~d}$ before the studies. Animals not exposed to $\mathrm{CCl}_{4}$ served as control. The experiments described in this report were conducted according to the Guide for the Care and Use of Laboratory animals.

Experimental design. Animals with cirrhosis were selected for the experiments once the presence of ascites was noticed. Then, rats were treated daily with tyrphostin AG 126 (Cal-Biochem Corp., La Jolla, CA) at a dose of $40 \mathrm{mg} / \mathrm{kg} / \mathrm{d}(n=7)$ or placebo $(n=9)$ intramuscularly for $5 \mathrm{~d}$, at which time the hemodynamic and analytical determinations were performed. Normal rats of the same age and receiving the same treatment as the cirrhotics were used to study the effect of AG $126(n=6)$ or placebo $(n=6)$ in animals without cirrhosis. The dose was chosen based on previous experiments from Dr. Levitzki's laboratory. In vivo studies showed that administration of tyrphostin AG 126 at a dose of $400 \mu \mathrm{g}$ per mouse before injection of LPS (1.5 mg per mouse) completely prevented TNF- $\alpha$ production and NO oxidation products nitrite and nitrate (NOx) synthesis, and reduced the lethality to $10 \%$ (23). Tyrphostins are synthetic PTK inhibitors that include several arylidene substances. The compounds belonging to the dihydroxy- and dimethoxybenzylidene malononitrile class of PTK inhibitors have good efficacy in vivo $(26,27)$.

Hemodynamic studies. Each animal was weighed and anesthetized with ketamine hydrochloride, $(100 \mathrm{mg} / \mathrm{kg}$ body wt, intramuscularly (Ketolar; Parke-Davis, Barcelona, Spain). MAP and portal pressure (PP) were evaluated by cannulating the exposed left femoral artery and superior mesenteric vein with PE-50 catheters connected to Combitrans ${ }^{\circledR}$ pressure transducers (B. Braun Melsungen AG, Melsungen, Germany). Permanent recordings of the MAP and then of the PP were made on a polygraph (model 6006; Letica). External zero reference level was placed at the midportion of the rats. To allow repeated measurements, stroke volume (SV) and cardiac output were measured by thermodilution, as previously described (28). Briefly, a thermistor was placed in the aortic arch just distal to the aortic valve, and the thermal indicator $(0.1 \mathrm{ml}$ of $5 \%$ dextrose/water) was injected into the right atrium through a PE-50 catheter placed into the jugular vein. The aortic thermistor was connected to a cardiac output computer (Experimetria MM Ltd., Budapest, Hungary). Blood temperature was maintained at $37.2 \pm 0.2^{\circ} \mathrm{C}$. A typical thermodilution curve would have a peak blood temperature value of $\sim-0.3^{\circ} \mathrm{C}$ with a rapid upslope and a smooth decay. At least three thermodilution curves were obtained for each cardiac output measurement, discarding those curves with unusual morphology. The final cardiac output value was obtained from the arithmetic mean of the computer results of at least two thermodilution curves. The cardiac output measurements were highly reproducible, with a coefficient of variability of $3.7 \pm 1.7 \%$. Cardiac index (CI) $\left(\mathrm{ml} \cdot \mathrm{min}^{-1} \cdot 100 \mathrm{~g}^{-1}\right)$ was calculated as cardiac output per $100 \mathrm{~g}$ body wt. SVR $\left(\mathrm{mmHg} \cdot \mathrm{min} \cdot \mathrm{ml}^{-1} \cdot 100 \mathrm{~g}\right.$ ) was calculated from MAP divided by CI.

PSS was quantified by an injection of $\sim 50,000{ }^{57} \mathrm{Co}$-labeled microspheres (15.5 $\pm 0.1 \mathrm{~mm}$; New England Nuclear, Boston, MA) into the spleen as previously described (29).

Measurements of TNF- $\alpha$. We used an immunoassay kit (BioSource, International, Camarillo, TX) to determine TNF- $\alpha$ concentrations in both serum and mesenteric lymph node (MLN) homogenates. This immunoassay, used for the in vitro determination of TNF- $\alpha$ in rat serum, recognizes both natural and recombinant rat TNF- $\alpha$. In brief, as reported by the manufacturer, this kit is a solid-phase sandwich ELISA. A specific anti-TNF- $\alpha$ antibody was coated onto the wells of the microtiter strips. Standards of known TNF- $\alpha$ contents, control specimens, and unknown samples were pipetted into the wells followed by the addition of biotinylated second antibody. After a first incubation and the removal of excess second antibody, streptavidin peroxidase was added. A substrate (tetramethyl benzidine) solution was then added to produce color. The intensity of this colored product is directly proportional to the concentration of TNF- $\alpha$ present in the sample. Absorbancy was read with a microtiter plate reader at $450 \mathrm{~nm}$. The minimum detectable dose of TNF- $\alpha$ for this kit is $4 \mathrm{pg} /$ $\mathrm{ml}$. It has cross-reactivity with mouse $(100 \%)$ and human TNF- $\alpha$ $(0.15 \%)$. No cross-reactivity has been observed with rat IFN- $\gamma$, mouse IL-1 $\beta$, IL-2, IL-4, IL-6, and IL-10. The recovery of TNF- $\alpha$ added to pooled rat serum averaged $104 \%$ (range $94-110 \%$ ) between 200 and $800 \mathrm{pg} / \mathrm{ml}$ of TNF- $\alpha$. The intra- and the interassay coefficients of variance are $2.6-2.7$ and $3.5-4.3 \%$, respectively. The correlation coefficient of the linear regression analysis of samples versus expected concentrations is 0.999 .

TNF- $\alpha$ was measured in serum and MLN samples obtained at the end of hemodynamic studies in AG 126- and placebo-treated animals.

Measurement of serum NO. NO was determined photometrically in serum by its oxidation products nitrite and nitrate using a colorimetric assay (Boehringer Mannheim, Mannheim, Germany). As described by the manufacturer, NO is detected in biological fluids via nitrite. The nitrate present in samples is reduced to nitrite by reduced nicotinamide adenine dinucleotide phosphate in the presence of the enzyme nitrate reductase. The nitrite formed reacts with sulfanilamide and $N$-(1-naphtyl)-ethyl-enediamine dihydrochloride to give a red-violet diazo dye. Finally, the diazo dye is measured on the basis of its absorbance at $550 \mathrm{~nm}$ using a microtiter plate reader $(30,31)$.

Statistics. All the observations are reported as mean \pm SEM. Statistical analyses were performed using the unpaired $t$ test and simple regression analysis, and the Spearman rank correlation coefficients were calculated

\section{Results}

Treatment was tolerated well, and no side effects were observed in the animals. Cirrhotic rats treated with tyrphostin AG 126 presented with a statistically significant increase in MAP $(123 \pm 3.7$ vs. $109.5 \pm 3.7 \mathrm{mmHg}, P=0.02)$ and SVR $\left(1.72 \pm 0.16\right.$ vs. $\left.1.15 \pm 0.05 \mathrm{mmHg} \cdot \mathrm{ml}^{-1} \cdot \min \cdot 100 \mathrm{~g}, P=0.01\right)$ in 


\section{MAP}

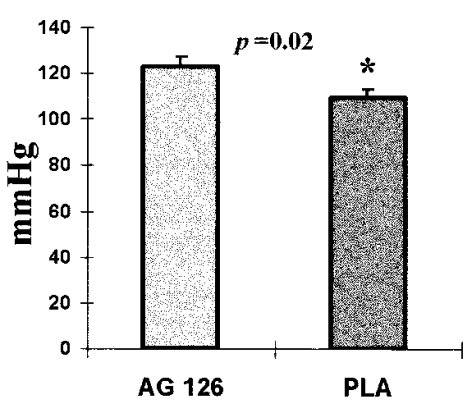

CI

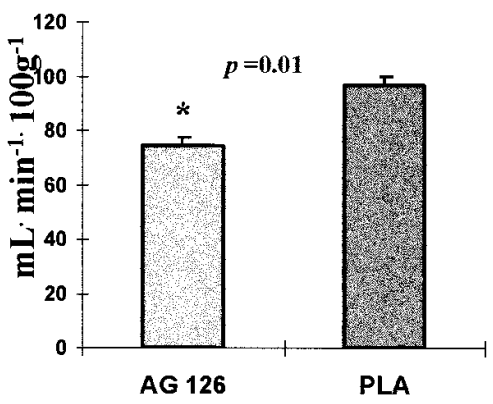

B

PP

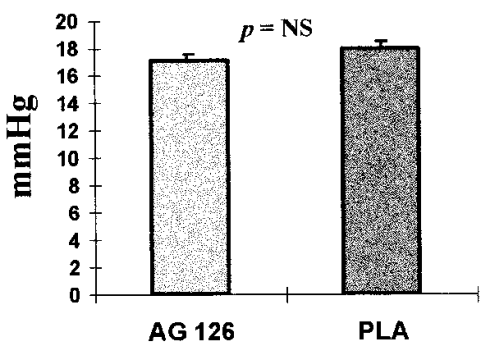

SVR

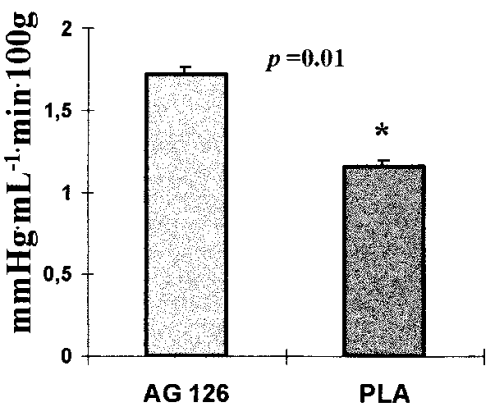

SV

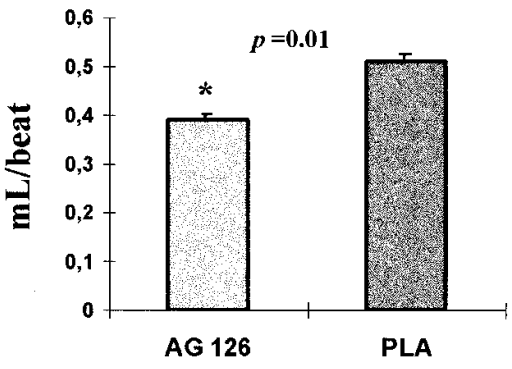

Figure 1. (A) Effect of tyrphostin AG 126 treatment on the systemic hemodynamics of ascitic cirrhotic rats with PHT. Animals treated with AG 126 show a significant increase in MAP and SVR, and a significant decrease in $\mathrm{CI}$ and $\mathrm{SV}$ in comparison with the placebo-treated rats. Data are shown in absolute values. (B) Effect of tyrphostin AG 126 treatment on the splanchnic hemodynamics of ascitic cirrhotic rats with PHT. Animals treated with AG 126 do not show any significant difference in PP (in absolute values) or PSS in comparison with the placebo-treated rats. $A G 126$, Cirrhotic rats treated with tyrphostin AG $126(n=$ 7). PLA, Cirrhotic rats treated with placebo $(n=9)$. comparison with the placebo-treated cirrhotic animals. On the other hand, the AG 126-treated rats showed a statistically significant decrease in CI $\left(74.2 \pm 5.5\right.$ vs. $96.7 \pm 5.2 \mathrm{ml} \cdot \mathrm{min}^{-1}$. $\left.100 \mathrm{~g}^{-1}, P=0.01\right)$ and SV $(0.39 \pm 0.02$ vs. $0.51 \pm 0.03 \mathrm{ml} / \mathrm{beat}$, $P=0.01$ ) compared to the placebo-treated rats (Fig. $1 A)$. No statistically significant differences were found regarding heart rate $(\mathrm{HR})(414 \pm 14$ vs. $384 \pm 10 \mathrm{bpm}, P>0.05)$. No significant changes were noticed in the splanchnic hemodynamics. As depicted in Fig. $1 B$, no statistical differences were observed in PP $(17.9 \pm 0.5$ vs. $17.1 \pm 0.8 \mathrm{mmHg}, P>0.05)$ or PSS $(56.7 \pm 12$ vs. $61.5 \pm 14 \%, P>0.05)$.

Tyrphostin AG 126 treatment did not exert any signifi- cant hemodynamic effect on control rats compared to the control placebo-treated animals ( $n=6$ in both groups) (MAP: $126 \pm 2$ vs. $126 \pm 1 \mathrm{mmHg}$; SVR: $3.96 \pm 0.4$ vs. $5.63 \pm 0.9$ $\mathrm{mmHg} \cdot \mathrm{ml}^{-1} \cdot \mathrm{min} \cdot 100 \mathrm{~g} ; \mathrm{CI}: 33.3 \pm 3$ vs. $25.8 \pm 5 \mathrm{ml} \cdot \mathrm{min}^{-1} \cdot 100$ $\mathrm{g}^{-1}$; SV: $0.22 \pm 0.01$ vs. $0.18 \pm 0.029 \mathrm{ml} / \mathrm{beat}$; HR: $441 \pm 32$ vs. $460 \pm 21 \mathrm{bpm}$; and PP: $6.1 \pm 1.2$ vs. $7.5 \pm 0.6 \mathrm{mmHg} ; P=\mathrm{NS}$ ) (Fig. 2).

Cirrhotic animals treated with placebo had a statistically lower MAP and SVR $(109.5 \pm 3.7$ vs. $126 \pm 1 \mathrm{mmHg}$, and $1.15 \pm 0.05$ vs. $\left.5.63 \pm 0.9 \mathrm{mmHg} \cdot \mathrm{ml}^{-1} \cdot \mathrm{min} \cdot 100 \mathrm{~g} ; P<0.01\right)$ and higher SV, CI, and PP $(0.51 \pm 0.03$ vs. $0.18 \pm 0.02 \mathrm{ml} / \mathrm{beat}$, $96.7 \pm 5.2$ vs. $25.8 \pm 5.0 \mathrm{ml} \cdot \mathrm{min}^{-1} \cdot 100 \mathrm{~g}^{-1}$, and $17.1 \pm 0.5$ vs. 
MAP

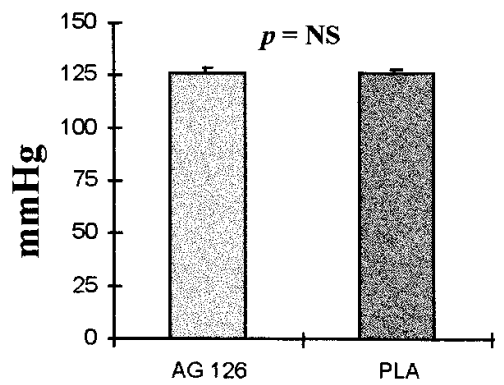

CI

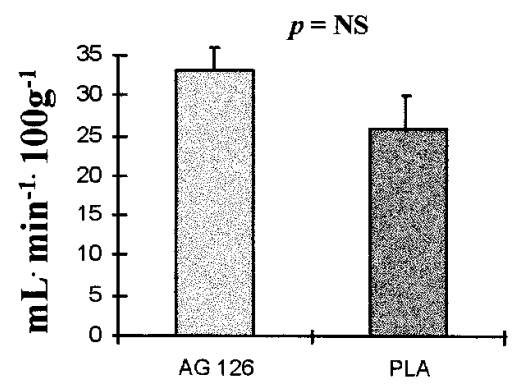

SVR

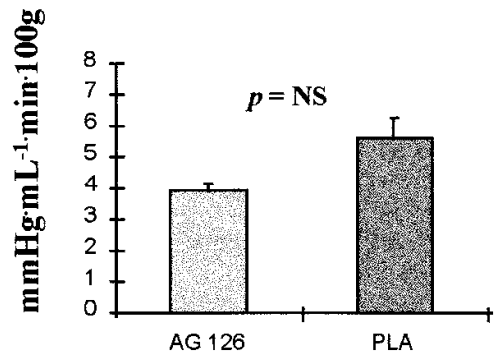

SV

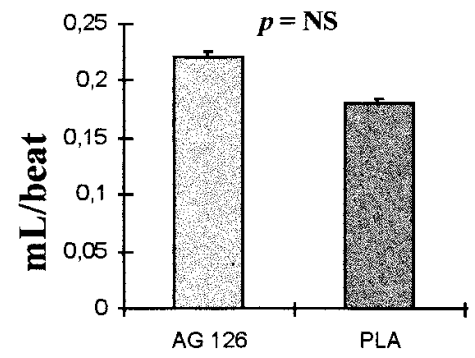

Figure 2. Effect of tyrphostin AG 126 treatment on the systemic hemodynamics of control (normal) rats. Animals treated with AG 126 do not show any significant difference in MAP, SVR, CI, or SV in comparison with the placebo-treated rats. Data are shown in absolute values. $A G$ 126, Control rats treated with tyrphostin AG $126(n=6)$. PLA, Control rats treated with placebo $(n=6)$.
$7.5 \pm 0.6 \mathrm{mmHg} ; P<0.001)$ compared to the control rats treated with placebo. No significant differences in MAP and HR were observed between cirrhotic animals treated with AG 126 and control rats treated with AG 126 (123 \pm 3.7 vs. $126 \pm 2$ $\mathrm{mmHg}$ and $414 \pm 14$ vs. $441 \pm 32 \mathrm{bpm} ; P=\mathrm{NS})$. Cirrhotic animals treated with AG 126 had a higher CI, SV, and PP $\left(74.2 \pm 5.5\right.$ vs. $33.3 \pm 3 \mathrm{ml} \cdot \mathrm{min}^{-1} \cdot 100 \mathrm{~g}^{-1}, 0.39 \pm 0.02$ vs. $0.22 \pm 0.01$ $\mathrm{ml} /$ beat, and $17.9 \pm 0.8$ vs. $6.08 \pm 1.2 \mathrm{mmHg} ; P<0.001)$, and lower SVR $\left(1.72 \pm 0.16\right.$ vs. $3.96 \pm 0.39 \mathrm{mmHg} \cdot \mathrm{ml}^{-1} \cdot \mathrm{min} \cdot 100 \mathrm{~g}$, $P<0.01)$ than control rats treated with AG 126 .

Although differences regarding serum TNF- $\alpha$ did not reach statistical significance ( $79 \pm 15$ vs. $97 \pm 27 \mathrm{pg} / \mathrm{ml}, P>0.05)$, cirrhotic animals treated with AG 126 presented with a significantly lower MLN TNF- $\alpha$ (222 \pm 47 vs. $439 \pm 59 \mathrm{pg} / \mathrm{ml}, P=$ $0.01)$ and serum NOx (15.8 \pm 1.1 vs. $21.3 \pm 1.5 \mu \mathrm{M}, P=0.01)$ concentrations in comparison with the placebo-treated cirrhotic rats (Fig. 3).

Control animals treated with AG 126 did not show any significant difference in serum TNF, MLN TNF, or serum NOx $(16.39 \pm 7.0$ vs. $13.13 \pm 7.9 \mathrm{pg} / \mathrm{ml}, 87.10 \pm 18.1$ vs. $152.0 \pm 48.4 \mathrm{pg} /$ $\mathrm{ml}$, and $21.2 \pm 2.7$ vs. $13.2 \pm 2.4 \mu \mathrm{M} ; P=\mathrm{NS}$ ) compared to the placebo-treated control rats.

No significant differences were observed in the degree of ascites or change in weight of rats, serum transaminases, bilirubin, urea, creatinine, alkaline phosphatase, $\gamma$-glutamyl transpeptidase, hematocrit, sodium, potassium, or proteins between AG 126 and placebo-treated animals.

Moreover, when data from all AG 126- and placebotreated rats were pooled together in a simple regression analysis, a significant correlation was found between MAP and NOx

\section{MLN TNF}

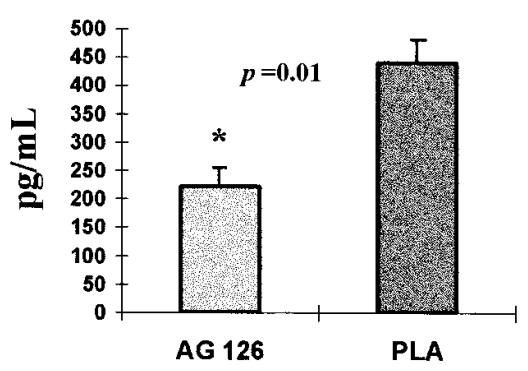

\section{Serum NOx}

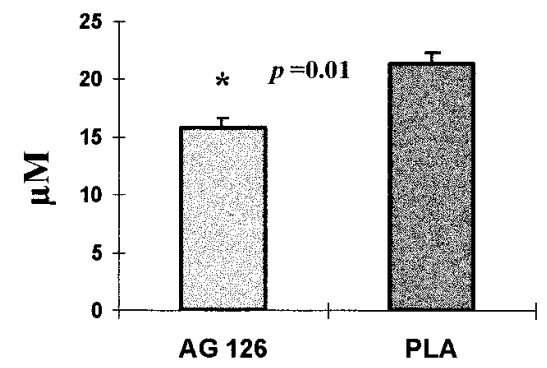

Figure 3. MLN TNF- $\alpha(M L N-T N F)$ and serum NOx levels of ascitic cirrhotic rats with PHT treated with tyrphostin AG 126 or placebo. Animals treated with AG 126 have significantly lower levels of both MLN-TNF and serum NOx in comparison with the placebo-treated rats. $A G 126$, Cirrhotic rats treated with tyrphostin AG 126 $(n=7)$. PLA, Cirrhotic rats treated with placebo $(n=9)$. 


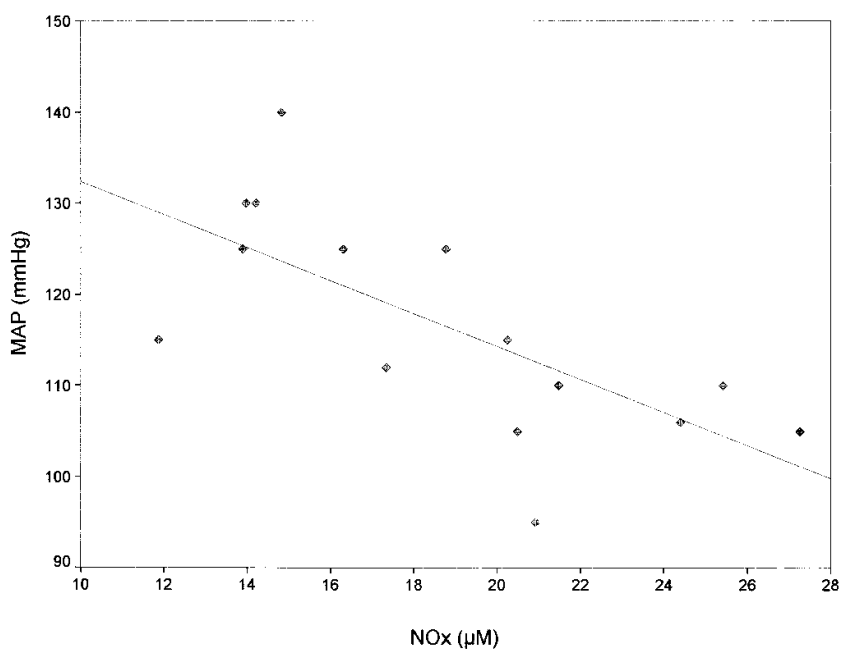

Figure 4. Correlation between MAP and serum NOx levels in ascitic cirrhotic rats with PHT. A statistically significant correlation $(\mathrm{R}=$ $-0.76 ; P<0.001)$ between MAP and serum NOx levels.

serum levels ( $\mathrm{R}=-0.76, P<0.001)$ (Fig. 4), MAP and MLN TNF- $\alpha(\mathrm{R}=-0.65, P=0.008)$ (Fig. 5), and serum TNF- $\alpha$ and NOx levels $(\mathrm{R}=0.62, P=0.003)$ (Fig. 6). A close correlation was noticed between serum NOx and MLN TNF- $\alpha(\mathrm{R}=0.46)$, but it did not reach statistical significance $(P=0.08)$.

\section{Discussion}

The pathogenesis of the HCS in patients and experimental models of liver disease has been of relevant interest in medical research, especially because of its serious consequences, including variceal hemorrhage, hepatopulmonary syndrome, portal-systemic encephalopathy, and ascites (1). Several investigators have reported previously that the L-arginine-derived $\mathrm{NO}$ is involved, at least in part, in the hemodynamic changes

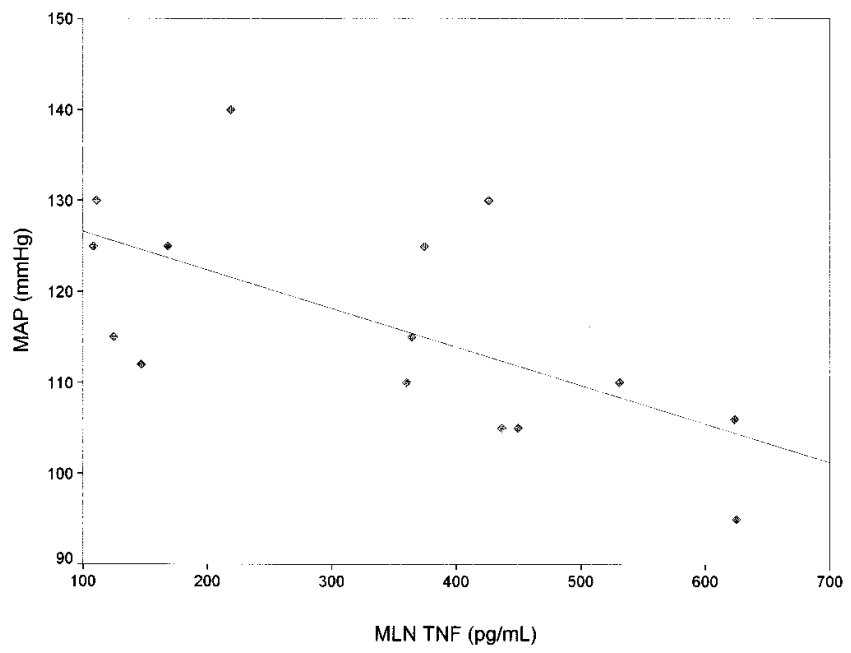

Figure 5. Correlation between MAP and MLN TNF- $\alpha$ (MLN-TNF) levels in ascitic cirrhotic rats with PHT. A statistically significant correlation $(\mathrm{R}=-0.65 ; P<0.008)$ between MAP and MLN-TNF.

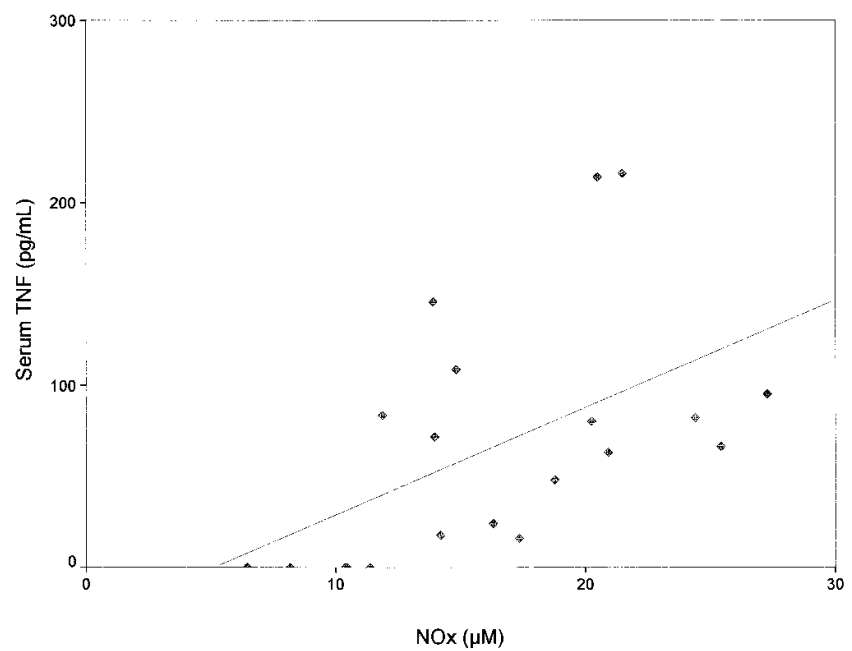

Figure 6. Correlation between serum TNF- $\alpha$ and serum NOx levels in ascitic cirrhotic rats with PHT. A statistically significant correlation $(\mathrm{R}=0.62 ; P=0.003)$ between serum TNF- $\alpha$ and serum NOx levels.

of this syndrome (2-5). Besides, it has been shown that the systemic hypotension elicited by TNF- $\alpha$ in mammals is possibly mediated by NO (15). In a recent study, it was demonstrated that $\mathrm{TNF}-\alpha$ blockade with specific polyclonal antibodies in an experimental model of PHT (partial ligation of the portal vein, or PVL) that mimics the hemodynamic features observed in liver cirrhosis, prevented and corrected in large part the clinical characteristics of the HCS (18). These findings were confirmed in a study performed in the same experimental model of PHT by using thalidomide, a derivative of glutamic acid which selectively inhibits TNF- $\alpha$ production (19).

Several authors found a role for TNF- $\alpha$ in hepatic pathophysiology, and showed that elevated concentrations of cytokines represent a characteristic feature of liver disease (32). TNF- $\alpha$ and IL- $1 \alpha$ are related to some of the metabolic consequences of both acute and chronic alcohol-induced liver disease (17), and their production is increased in chronic liver disease (16). The liver is a major site for the synthesis and clearance of several cytokines (33). They are involved in the onset of intrahepatic immune responses, in liver regeneration, and in the fibrotic and cirrhotic transformation of the liver due to chronic chemical injury (as in the experimental model used in this report) or viral infection (33). NO may act as a messenger molecule for LPS and cytokine-induced cGMP biosynthesis in liver cells (34). Endotoxins have not been detected in arterial samples of PVL rats (35). However, the hypothesis that endotoxin does play a role in the hyperdynamic circulation of this experimental model cannot be completely ruled out. Several investigators have shown that $\mathrm{TNF}-\alpha$ receptor is capable of signal transduction (36). Monocytes from alcoholic hepatitis patients have significantly increased spontaneous and LPSstimulated TNF- $\alpha$ release compared to monocytes from healthy volunteers (37).

PHT promotes bacterial translocation to the MLN. In most cases, these bacteria are contained within these nodes without invading the blood or other organs $(38,39)$. Therefore, it is possible that the mononuclear cell may be activated within the lymph nodes without detection of circulating endotoxins. Re- 
cently, emphasis has been placed on the fact that sepsis is one example of a systemic inflammatory response that can be triggered not only by infection but by noninfectious disorders as well (40). Microorganisms may invade the bloodstream or may proliferate locally and release various substances, such as endotoxin (LPS), teicoic acid antigen, or exotoxins, which are structural components that stimulate the release of endogenous mediators of sepsis from plasma precursors or cells (41). LPS induces protein tyrosine phosphorylation (20) in macrophages, as well as the generation of eicosanoids (42) and NO, and PTK inhibitors such as tyrphostins inhibit these events. Additionally, TNF- $\alpha-$ mediated signaling events are also blocked by PTK inhibitors (43). Some of the toxic manifestations of LPS seem to be mediated by NO (22). NO production is stimulated by LPS and inhibited by tyrphostins (44). Thus, these agents can suppress both the production of TNF- $\alpha$ and/or their induced effects.

Tyrphostin AG 126 is one of the most potent inhibitors of TNF- $\alpha$ production and it also inhibits the in vitro production of NOx (23). This class of PTK inhibitors has good efficacy in vivo $(26,27)$. Previous experiments have shown no visible toxic manifestations or life-shortening in animals treated with AG 126. Administration up to 30 times the dose given in the experiments did not show any toxicity (23). This observation is confirmed in our experiments where hematological and biochemical findings were similar in both AG 126- and placebotreated rats, and no side effects were noticed. The administration of AG 126 before LPS treatment inhibited the increase in the concentration of serum TNF- $\alpha$, but administration of AG $1262 \mathrm{~h}$ after LPS had almost no protective effect (23).

Cirrhosis differs from the septic and prehepatic PHT-PVL models because, in the former, the time of onset of stimulation is not precise: cirrhosis shows chronic induction of $\mathrm{TNF}_{-} \alpha$ formation and exposure to its metabolic and hemodynamic changes. This study, using an experimental rat model of liver cirrhosis with PHT induced by chronic inhalation of $\mathrm{CCl}_{4}$, demonstrates that treatment with tyrphostin AG 126, a selective PTK inhibitor, increases MAP and SVR and decreases CI, SV, MLN TNF- $\alpha$ levels, and serum NOx in these animals. Therefore, this treatment corrects in large part the hemodynamic abnormalities which characterize the HCS of liver cirrhosis. Serum TNF- $\alpha$ levels were not significantly different in AG 126- and placebo-treated animals. One possible explanation for this finding could be that, once TNF- $\alpha$ production is induced, the inhibitory effect of AG 126 on TNF- $\alpha$ synthesis is much more reduced. Nevertheless, AG 126 is able to inhibit tyrosine phosphorylation and NO production. The results from this study also show a significant correlation between MAP and NOx serum levels, MAP and MLN TNF- $\alpha$, and serum TNF- $\alpha$ and NOx levels. A close correlation was also observed between serum NOx and MLN TNF- $\alpha$, although it did not reach statistical significance.

The findings we report here support the hypothesis recently suggested that TNF- $\alpha$ has a possible role in the pathogenesis of the hemodynamic changes observed in PHT (18, $19)$, and that increased NO synthesis associated with increments in TNF- $\alpha$ activity is responsible, at least in part, for the observed vasodilatation.

In summary, this study, performed in ascitic cirrhotic rats with PHT induced by $\mathrm{CCl}_{4}$ inhalation, shows that treatment with a specific PTK inhibitor such as tyrphostin AG 126 significantly ameliorates the hyperdynamic state and reduces MLN
TNF- $\alpha$ and serum NOx levels. We conclude that tyrosine kinases, and the signaling pathways in which they participate, may be implicated in the pathophysiologic events induced by TNF- $\alpha$ and NO and in the hemodynamic abnormalities observed in cirrhosis.

\section{References}

1. Genecin, P., and R.J. Groszmann. 1993. Portal hypertension. In Diseases of the Liver, 7th ed. E. Schiff and L. Schiff, editors. J.B. Lippincott Co., Philadelphia, PA. 2:935-973.

2. Pizcueta, P., J.M. Pique, M. Fernandez, J. Bosch, J. Rodes, B.J.R. Whittle, and S. Moncada. 1992. Modulation of the hyperdynamic circulation of cirrhotic rats by nitric oxide inhibition. Gastroenterology. 103:1909-1915.

3. Whittle, B.J.R., and S. Moncada. 1992. Nitric oxide: the elusive mediator of the hyperdynamic circulation of cirrhosis? Hepatology. 16:1089-1092.

4. Lee, F.Y., A. Albillos, L.A. Colombato, and R.J. Groszmann. 1992. The role of nitric oxide in the vascular hyporesponsiveness to methoxamine in portal hypertensive rats. Hepatology. 16:1043-1048.

5. Pizcueta, M.P., J.M. Pique, J. Bosch, B.J.R. Whittle, and S. Moncada. 1992. Effects of inhibiting nitric oxide biosynthesis on the systemic and splanchnic circulation of rats with portal hypertension. Br. J. Pharmacol. 105:184-190.

6. Old, L.J. 1985. Tumor necrosis factor (TNF- $\alpha$ ). Science (Wash. DC). 230: 630-632.

7. Stephens, K.E., A. Ishizaka, J.W. Larryk, and T.A. Raffin. 1988. Tumor necrosis factor causes increased pulmonary permeability and edema. Comparison to septic acute lung injury. Am. Rev. Respir. Dis. 137:1364-1370.

8. Gamble, J.R., J.M. Harlan, S.J. Klebanoff, and M.A. Vadas. 1985. Stimulation of the adherence of neutrophils to umbilical vein endothelium by human recombinant tumor necrosis factor. Proc. Natl. Acad. Sci. USA. 82:8667-8671.

9. Frater Schroeder, M., W. Risau, R. Hallmann, P. Gautschi, and P. Bohlen. 1987. Tumor necrosis factor type alpha, a potent inhibitor of endothelial cell growth in vitro, is angiogenic in vivo. Proc. Natl. Acad. Sci. USA. 84:5277-5281.

10. Johnson, J., K.L. Brigham, G. Jesmok, and B. Meyrick. 1991. Morphologic changes in lungs of anesthetized sheep following intravenous infusion of recombinant tumor necrosis factor alpha. Am. Rev. Respir. Dis. 144:179-186.

11. Kelly, J. 1990. Cytokines of the lung. Am. Rev. Respir. Dis. 141:765-788.

12. Gross, S.S., E.A. Jaffe, R. Levi, and R.G. Kilbourn. 1991. Cytokine-activated endothelial cells express an isotype of nitric oxide synthase which is tetrahydrobiopterin-dependent, calmodulin-independent and inhibited by arginine analogs with a rank-order of potency characteristic of activated macrophages. Biochem. Biophys. Res. Commun. 178:823-829.

13. Kilbourn, R.G., and P. Belloni. 1990. Endothelial cell production of nitrogen oxides in response to interferon gamma in combination with tumor necrosis factor, interleukin-1, or endotoxin. J. Natl. Cancer Inst. (Bethesda). 82: $772-776$.

14. Westenfelder, C., R. Taintor, Z. Vavrin, C. Kablitz, R.L. Baranowski, J.H. Ward, R.L. Menlove, M.P. McMurry, J.P. Kushner, and W.E. Samlowski. 1992. Evidence for cytokine-inducible nitric oxide synthesis from L-arginine in patients receiving interleukin-2 therapy. J. Clin. Invest. 89:867-877.

15. Kilbourn, R.G., S.S. Gross, A. Jubran, J. Adams, O.W. Griffith, R. Levi, and R.F. Lodato. 1990. $\mathrm{N}^{\mathrm{G}}$-Methyl-L-arginine inhibits tumor necrosis factorinduced hypotension: implications for the involvement of nitric oxide. Proc. Natl. Acad. Sci. USA. 87:3629-3632.

16. Yoshioka, K., S. Kakumu, M. Arao, Y. Tsutsumi, and M. Inque. 1989. Tumor necrosis factor-alpha production by peripheral blood mononuclear cells of patients with chronic liver disease. Hepatology. 10:769-773.

17. Khoruts, A., L. Stahnke, C. McClain, G. Logan, and J.I. Allen. 1991. Circulating tumor necrosis factor, interleukin-1 and interleukin-6 concentrations in chronic alcoholic patients. Hepatology. 13:267-276.

18. Lopez-Talavera, J.C., W. Merrill, and R.J. Groszmann. 1995. Tumor necrosis factor-alpha: a major contributor to the hyperdynamic circulation in prehepatic portal hypertensive rats. Gastroenterology. 108:761-767.

19. Lopez-Talavera, J.C., G. Cadelina, J. Olchowski, W. Merrill, and R.J. Groszmann. 1996. Thalidomide inhibits tumor necrosis factor-alpha, decreases nitric oxide synthesis and ameliorates the hyperdynamic circulatory syndrome in portal-hypertensive rats. Hepatology. 23:1616-1621.

20. Weinstein, S.L., M.R. Gold, and A.L. De Franco. 1991. Bacterial lipopolysaccharide stimulates protein tyrosine phosphorylation in macrophages. Proc. Natl. Acad. Sci. USA. 88:4148-4152.

21. Vietor, I., P. Schwenger, W. Li, J. Schlessinger, and J. Vilcek. 1993. Tumor necrosis factor-induced activation and increased tyrosine phosphorylation of mitogen-activated protein (MAP) kinase in human fibroblasts. J. Biol. Chem. 268:18994-18999.

22. Kilbourn, R.G., and O.W. Griffith. 1992. Overproduction of nitric oxide in cytokine-mediated and septic shock. J. Natl. Cancer Inst. (Bethesda). 84:827831 .

23. Novogrodsky, A., A. Vanichkin, M. Patya, A. Gazit, N. Osherov, and A. Levitzki. 1994. Prevention of lipopolysaccharide-induced lethal toxicity by ty- 
rosine kinase inhibitors. Science (Wash. DC). 264:1319-1322.

24. Lopez-Novoa, J.M. 1988. Pathophysiological features of the carbon tetrachloride/phenobarbital model of experimental liver cirrhosis in rats. In The Kidney in Liver Disease, 3rd ed. M. Epstein, editor. Elsevier Science Publishing Co. Inc., New York. 309-327.

25. Sieber, C.C., J.C. Lopez-Talavera, and R.J. Groszmann. 1993. Role of nitric oxide in the in vitro splanchnic vascular hyporeactivity in ascitic cirrhotic rats. Gastroenterology. 104:1750-1754.

26. Yoneda, T., R.M. Lyall, and M.M. Alsina. 1991. The anti-proliferative effects of tyrosine kinase inhibitors on a human squamous cell carcinoma in vitro and in nude mice. Cancer Res. 51:4430-4435.

27. Meydan, N., T. Grunberger and H. Dadi. 1996. Inhibition of acute lymphoblastic leukaemia by a Jak-2 inhibitor. Nature (Lond.). 379:645-648.

28. Colombato, L.A., A. Albillos, and R.J. Groszmann. 1991. Temporal relationship of peripheral vasodilatation, plasma volume expansion and the hyperdynamic circulatory state in portal-hypertensive rats. Hepatology. 15:323328

29. Blei, A.T., D.J. O'Reilly, and J. Gottstein. 1984. Portal-systemic shunting and the hemodynamic effects of nitroglycerin in the rat. Gastroenterology. 86:1428-1436.

30. Edelman, G.M., and J.A. Gally. 1992. Nitric oxide: linking space and time in the brain. Proc. Natl. Acad. Sci. USA. 89:11651-11652.

31. Stamler, J.S., D.J. Singel, and J. Loscalzo. 1992. Biochemistry of nitric oxide and its redox-activated forms. Science (Wash. DC). 258:1898-1902.

32. Tilg, H., A. Wilmer, W. Vogel, M. Herold, B. Nolchen, G. Judmaier, and C. Huber. 1992. Serum levels of cytokines in chronic liver diseases. Gastroenterology. 103:264-274.

33. Andus, T., J. Bauer, and W. Gerok. 1991. Effects of cytokines on the liver. Hepatology. 13:364-375.

34. Billiard, T.R., R.D. Curran, B.G. Harbrecht, J. Stadler, D.L. Williams, J.B. Ochoa, M. Di Silvio, R.L. Simmons, and S.A. Murray. 1992. Association between synthesis and release of cGMP and nitric oxide biosynthesis by hepatocytes. Am. J. Physiol. 262:C1077-C1082.
35. Mehta, R., J. Gottstein, W. Patrick Zeller, R. Lichtenberg, and A.T. Blei. 1990. Endotoxin and the hyperdynamic circulation of portal vein-ligated rats. Hepatology. 12:1152-1156.

36. Tartaglia, L.A., M. Rothe, Y.-F. Hu, and D.V. Goeddel. 1993. Tumor necrosis factor's cytotoxic activity is signaled by the p55 TNF- $\alpha$ receptor. Cell. 73:213-216.

37. Deviere, J., J. Content, C. Denys, P. Vandenbussche, L. Schandene, J. Wybran, and E. Dupont. 1990. Excessive in vitro bacterial lipopolysaccharideinduced production on monokines in cirrhosis. Hepatology. 11:628-634.

38. Sorell, W.T., E.M.M. Quigley, G. Jin, T.J. Johnson, and L.F. Rikkers. 1993. Bacterial translocation in the portal-hypertensive rat: studies in basal conditions and on exposure to hemorrhagic shock. Gastroenterology. 104:17221726

39. Garcia-Tsao, G., A. Albillos, G.E. Barden, and A.B. West. 1993. Bacterial translocation in acute and chronic portal hypertension. Hepatology. 17: 1081-1085.

40. American College of Chest Physicians/Society of Critical Care Medicine Consensus Conference: definitions for sepsis and organ failure and guidelines for the use of innovative therapies in sepsis. 1992. Crit. Care Med. 20:864-874.

41. Parrillo, J.E. 1993. Pathogenetic mechanisms of septic shock. N. Engl. J. Med. 328:1471-1477.

42. Glaser, K.B., A. Sung, J. Bauer, and B.M. Weichman. 1993. Regulation of eicosanoid biosynthesis in the macrophage. Involvement of protein tyrosine phosphorylation and modulation by selective protein tyrosine kinase inhibitors. Biochem. Pharmacol. 1993:711-721.

43. Levitzki, A. 1992. Tyrphostins: tyrosine kinase blockers as novel antiproliferative agents and dissectors of signal transduction. FASEB (Fed. Am. Sco. Exp. Biol.) J. 6:3275-3282.

44. Dong, Z., X. Qi, K. Xie, and I.J. Fidler. 1993. Protein tyrosine kinase inhibitors decrease induction of nitric oxide synthase activity in lipopolysaccharide-responsive and lipopolysaccharide-nonresponsive murine macrophages. $J$. Immunol. 151:2717-2724. 